\title{
COMPRIMENTO E ÍNDICE DE EXPANSÃO RADIAL DO HIPOCÓTILO DE CULTIVARES DE SOJA
}

\author{
HYPOCOTYL LENGTH AND SWELLING INDEX OF SOYBEAN CULTIVARS
}

\author{
José Antonio Costa ${ }^{1}$ João Leonardo Fernandes Pires ${ }^{2}$ André Luis Thomas ${ }^{3}$ Marilac Alberton $^{4}$
}

\section{RESUMO}

A emergência da plântula de soja é função do hipocótilo, responsável pela elevação dos cotilédones acima da superficie do solo. Quanto maior o comprimento e diâmetro do hipocótilo, maior é a capacidade da plântula para emergir e superar a resistência provocada pela profundidade de semeadura elou encrostamento do solo. O presente experimento foi conduzido com o objetivo de avaliar o comprimento e o índice de expansão radial (IER) do hipocótilo de cultivares de soja, em diferentes tamanhos de sementes. $O$ trabalho foi realizado na Faculdade de Agronomia da Universidade Federal do Rio Grande do Sul (FA/UFRGS). Foi quantificado o comprimento e IER do hipocótilo das plântulas de 17 cultivares em três tamanhos de sementes (> 6,3mm; entre 5,6 e 6,3mm e entre 4,75 e 5,6mm de diâmetro). Os cultivares tiveram médias entre 8 e $11 \mathrm{~cm}$ de comprimento do hipocótilo. As sementes de maior tamanho originaram plântulas com hipocótilo mais curto do que as sementes de tamanho intermediário e pequeno. Os IERs do hipocótilo dos cultivares foram diferentes e variaram de acordo com o tamanho de sementes. Houve respostas crescentes de IER do hipocótilo com o acréscimo no tamanho das sementes.

Palavras-chave: Glycine $\max ($ L.) Merrill, emergência, tamanho de semente.

\section{SUMMARY}

The soybean seedling emergence is a function of the hypocotyl, responsible for the cotyledon elevation above the soil surface. The greater the hypocotyl length and diameter, the greater the seeddlings' capacity to emerge and overcome the resistence do to the soil surface crusting. The purpose of this work was to evaluate the hypocotyl length and swelling index (HSI) of soybean cultivars in different seed size. The experiment was performed at the Faculdade de Agronomia da Universidade Federal do Rio Grande do Sul (FA/UFRGS). The hypocotyl length and HSI was determined in seventeen cultivars in three seed sizes (> 6.3mm; between 5.6 and $6.3 \mathrm{~mm}$ and between 4.75 and $5.6 \mathrm{~mm}$ in diameter). The cultivars had an average hypocotyl length between 8 and $11 \mathrm{~cm}$. The larger seeds produced seedlings with shorter hypocotyls, compared to medium-sized or small seeds, which produced longer ones. The hypocotyl HSI increased with the increase in seed size.

Key words: Glycine $\max ($ L.) Merrill, emergence, seed size.

\section{INTRODUÇÃO}

O estabelecimento da população adequada de plantas de soja é uma das etapas importantes para a obtenção de rendimentos elevados. Inúmeros fatores contribuem para a redução no número de plantas na lavoura como, por exemplo: baixa qualidade fisiológica e pequena quantidade de reservas nas sementes; ataque de pragas e disponibilidade hídrica inadequada.

Outra causa da baixa população de plantas em lavouras de soja é o encrostamento do solo (aumento da densidade da camada superficial) que ocorre depois de precipitações pluviais intensas em solo descoberto. $\mathrm{O}$ solo encrostado é uma barreira física que dificulta e/ou impede a emergência das plântulas e, conseqüentemente, o seu estabelecimento (HANKS \& THORP, 1957; KNITTLE \& BURRIS, 1979; BILBRO \& WANJURA, 1982; HOWLE \& CAVINESS, 1988). O hipocótilo é importante durante a emergência das plântulas de soja pois é responsável pela elevação dos cotilédones e do epicótilo acima da superfície do solo (KNITTLE \& BURRIS, 1979). Além do encrostamento superficial, a profundidade de semeadura (no que se refere ao peso exercido pelo próprio solo), ou qualquer

\footnotetext{
${ }^{1}$ Engenheiro Agrônomo, PhD., Professor Titular, Departamento de Plantas de Lavoura, Faculdade de Agronomia, Universidade Federal do Rio Grande do Sul (UFRGS), Caixa Postal 776, 90001-970, Porto Alegre, RS. Bolsista do CNPq. Autor para correspondência.

${ }^{2}$ Engenheiro Agrônomo, MSc., Pós-graduando em Agronomia-Fitotecnia, UFRGS. Bolsista do CNPq.

${ }^{3}$ Engenheiro Agrônomo, MSc., Professor Assistente, Departamento de Plantas de Lavoura, Faculdade de Agronomia, UFRGS.

${ }^{4}$ Engenheiro Agrônomo, M.Sc.
} 
outro fator que exerça força contrária ao crescimento do hipocótilo, constituem limitações.

O comprimento e IER (que é proporcional ao diâmetro) do hipocótilo das plântulas são medidas do crescimento que estão relacionadas com a capacidade das mesmas em emergir, vencendo esta barreira, uma vez que o hipocótilo deve crescer em comprimento, de modo a superar a profundidade de semeadura, e em diâmetro para aumentar sua força e habilidade de suportar, sem deformações, as resistências causadas pelo peso dos cotilédones e pelo encrostamento do solo.

O hipocótilo das plântulas de soja responde às resistências físicas com a diminuição do tamanho e o aumento do diâmetro (KNITTLE \& BURRIS, 1979). Em condições de solo não encrostado, a limitação à emergência seria devido ao alongamento do hipocótilo. As plântulas originárias de cultivares ou sementes de tamanhos que proporcionam taxas mais altas de alongamento do hipocótilo emergiriam mais rapidamente do que as que apresentam taxas mais baixas. Entretanto, o diâmetro ou expansão radial do hipocótilo são mais importantes no caso do solo apresentar uma crosta superficial (KNITTLE \& BURRIS, 1979).

$\mathrm{Na}$ literatura, existem resultados que se referem à importância do tamanho da semente no crescimento do hipocótilo e, conseqüentemente, na emergência das plântulas de soja. São relatados também efeitos relacionados a diferenças genéticas, influências de temperaturas e resistências físicas (EDWARDS \& HARTWIG, 1971; BURRIS et al., 1973; JOHNSON \& LUEDDERS, 1974).

Os objetivos do trabalho foram avaliar o comprimento e índice de expansão radial do hipocótilo de cultivares de soja, em diferentes tamanhos de sementes.

\section{MATERIAL E MÉTODOS}

O experimento foi conduzido no laboratório de sementes do Departamento de Plantas de Lavoura da Faculdade de Agronomia da UFRGS, Porto Alegre, RS. Foram utilizadas sementes dos cultivares FT Abyara, Bragg, BR 4, CEP 12 Cambará, CEP 16 Timbó, CEP 20 Guajuvira, CEP 26 Umbu, Cobb, EMBRAPA 19, IAS 4, IAS 5, IPAGRO 21, Ivorá, RS 5 Esmeralda, RS 6 Guassupí, RS 7 Jacuí e RS 9 Itaúba, limpas e classificadas por meio de sucessivas peneiragens, em tamanhos maiores que $6,3 \mathrm{~mm}$ (retidas em peneiras com furos quadrados com $6,3 \mathrm{~mm}$ de lado), entre 5,6 e $6,3 \mathrm{~mm}$ (as que passaram pela peneira com furos de $6,3 \mathrm{~mm}$ de lado e foram retidas na peneira com furos de $5,6 \mathrm{~mm}$ de lado) e entre 4,75 e $5,6 \mathrm{~mm}$ de diâmetro (as que passaram pela peneira com furos de $5,6 \mathrm{~mm}$ de lado e foram retidas na peneira com furos de $4,75 \mathrm{~mm}$ de lado).

As sementes de diâmetros entre 4,75 e $5,6 \mathrm{~mm}$ foram referidas como de $5,2 \mathrm{~mm}$, as entre 5,6 e $6,3 \mathrm{~mm}$ como $6,0 \mathrm{~mm}$ e as maiores que $6,3 \mathrm{~mm}$ como $6,7 \mathrm{~mm}$, tendo por base o diâmetro médio de cada classe.

O método para determinar o comprimento do hipocótilo das plântulas de soja foi o mesmo descrito por BURRIS \& FEHR (1971). As sementes foram tratadas com fungicida específico para a soja e envoltas em papel substrato embebido com água destilada por 24 horas, para que iniciassem o processo de germinação. Passado este período, as sementes, que se encontravam com radícula de $3 \mathrm{~mm}$, foram distribuídas sobre duas folhas de papel substrato (19 x 28cm), umedecido com água destilada. A distribuição foi feita posicionando 10 sementes em linha, a $4 \mathrm{~cm}$ da borda superior das folhas. As extremidades das radículas ficaram voltadas para baixo. Estas sementes foram cobertas com duas folhas de papel substrato, enroladas e colocadas em recipientes (bandejas) com lâmina de água destilada de $3 \mathrm{~cm}$, que foram fechados e permaneceram em germinador, no escuro, à temperatura constante de $25^{\circ} \mathrm{C}$, durante sete dias. Cada rolo foi considerado como uma repetição, sendo utilizadas cinco repetições para cada tratamento.

Os hipocótilos das plântulas tiveram o comprimento medido, após sete dias, da extremidade do gancho plumular até o início da raiz principal (onde se observa o aparecimento das raízes secundárias). A média do comprimento dos hipocótilos de cada rolo (repetição) foi considerada como valor representativo daquela repetição.

Para determinação do IER, obteve-se a massa do hipocótilos das plântulas, sendo a massa média de cada repetição o valor considerado para o cálculo do IER, de acordo com a fórmula descrita por KNITTLE \& BURRIS (1979): o IER do hipocótilo foi determinado pela razão entre a massa fresca $(\mathrm{mg})$ e o comprimento do hipocótilo $(\mathrm{cm})$.

Os dados obtidos foram submetidos à análise de variância pelo teste $\mathrm{F}$, sendo as diferenças entre médias de tratamentos comparadas pelo teste de Duncan em nível de 5\% de probabilidade. Utilizou-se análise de regressão quando comparou-se dados provenientes de sementes com diferentes tamanhos.

\section{RESULTADOS E DISCUSSÃO}

Em relação ao comprimento do hipocótilo, os cultivares e os tamanhos de sementes diferenciaram-se estatisticamente, mas não houve interação. 
Os cultivares CEP 16 Timbó, CEP 26 Umbu, RS 5 Esmeralda e RS 9 Itaúba tiveram hipocótilos com maiores comprimentos, sendo que o cultivar BR 4 apresentou o menor comprimento (tabela 1).

Tabela 1 - Comprimento do hipocótilo de cultivares de soja na média de três tamanhos de sementes. FA/UFRGS, Porto Alegre

\begin{tabular}{lc}
\hline \multicolumn{1}{c}{ Cultivares } & \\
\cline { 2 - 2 } FT Abyara & Comprimento do hipocótilo $(\mathrm{cm})$ \\
Bragg & $9,94 \mathrm{c} \mathrm{de} \mathrm{f}^{*}$ \\
BR 4 & $10,01 \mathrm{c} \mathrm{de}$ \\
CEP 12 Cambará & $8,37 \mathrm{~g}$ \\
CEP 16 Timbó & $9,26 \mathrm{ef}$ \\
CEP 20 Guajuvira & $11,40 \mathrm{a}$ \\
CEP 26 Umbu & $10,09 \mathrm{~cd}$ \\
Cobb & $11,67 \mathrm{a}$ \\
EMBRAPA 19 & $10,17 \mathrm{~cd}$ \\
IAS 4 & $10,61 \mathrm{bc}$ \\
IAS 5 & $9,94 \mathrm{cdef}$ \\
IPAGRO 21 & $9,47 \mathrm{def}$ \\
Ivorá & $9,63 \mathrm{def}$ \\
RS 5 Esmeralda & $9,19 \mathrm{f}$ \\
RS 6 Guassupí & $11,61 \mathrm{a}$ \\
RS 7 Jacuí & $11,11 \mathrm{ab}$ \\
RS 9 Itaúba & $9,80 \mathrm{def}$ \\
\end{tabular}

*Médias seguidas de mesma letra não diferem significativamente pelo teste de Duncan a 5\% de probabilidade.

Os tamanhos de sementes que originaram as plântulas com hipocótilo mais longos foram de $6,0 \mathrm{~mm}$ e $5,2 \mathrm{~mm}$, os quais não foram diferentes estatisticamente. As sementes com diâmetro de $6,7 \mathrm{~mm}$ originaram plântulas com hipocótilos mais curtos (figura 1).

O comprimento do hipocótilo apresentado pelos cultivares testados não seria limitante a emergência da soja, quando semeada de acordo com as recomendações para a cultura. A profundidade de semeadura recomendada para soja é de 2,5 a $5,0 \mathrm{~cm}$ (REUNIÃO..., 1998), inferior ao comprimento do hipocótilo da BR 4, cultivar que apresentou o menor comprimento (tabela 1). No entanto, cabe salientar que o experimento foi conduzido em condições que não impuseram impedimento físico ao crescimento do hipocótilo. Portanto, para que os resultados sejam transferidos para condições de lavoura, onde é comum a presença de encrostamento, é importante que sejam avaliadas outras características relacionadas ao hipocótilo como o IER, também simulando estas condições.

Neste sentido, os cultivares e os tamanhos de semente mostraram diferenças estatísticas quanto resposta menor ao incremento do diâmetro da se-

ao IER do hipocótilo.

A magnitude da variação do IER em função do tamanho de semente, possibilita a divisão dos cultivares

em dois

grupos: 1)

aqueles

que apre-

sentaram

regulari-

dade de

compor-

tamento,

aumen-

tando

IER

cada mi

límetro de

acréscimo

no diâ-

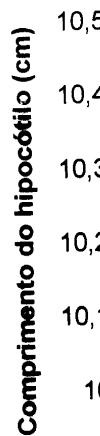

9,9

5

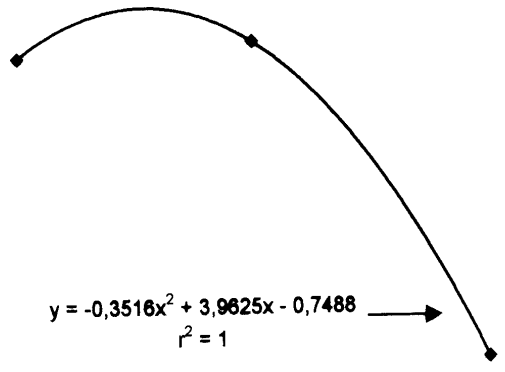

metro da Figura 1 - Comprimento do hipocótilo em função do diâmetro semente:

Grupo 1: das sementes, média de 17 cultivares de soja. FaculFT Abya-

ra, RS 6 Guassupí, CEP 26 Umbu, RS 7 Jacuí e IPAGRO $21 \mathrm{com}$ acréscimos de 4,1 a $5 \mathrm{mg} / \mathrm{cm}$ (figura 2a); IAS 4, BR 4 e RS 9 Itaúba, com acréscimos de $6 \mathrm{mg} / \mathrm{cm}$ (figura 2b); CEP 12 Cambará, CEP 16 Timbó, IAS 5, Bragg e Ivorá, com acréscimos de 7 a $11 \mathrm{mg} / \mathrm{cm}$ (figura $2 \mathrm{c}$ ); 2) aqueles que não apresentaram essa regularidade de resposta: Grupo 2: a) EMBRAPA 19, que apresentou maior IER do hipocótilo nas plântulas provenientes de sementes com diâmetro médio de $6,0 \mathrm{~mm}$, valor intermediário para as provenientes de sementes com $6,7 \mathrm{~mm}$ e menor valor para as oriundas das sementes de $5,2 \mathrm{~mm}$; b) Cobb, RS 5 Esmeralda e CEP 20 Guajuvira, cujos valores de IER não diferiram com a variação no diâmetro das sementes (tabela 2).

O aumento no IER do hipocótilo observado nas plântulas originadas das sementes maiores (figura $2 \mathrm{a}-\mathrm{c}$ ) pode ser uma resposta à pressão exercida pelo peso dos cotilédones dessas sementes, pois KNITTLE \& BURRIS (1979) observaram que o hipocótilo aumenta o diâmetro com o acréscimo da pressão exercida sobre ele. Porém, maiores estudos seriam necessários para verificar se não há algum outro fator provocando esta resposta.

O comportamento distinto de cultivares como RS 6 Guassupí (figura 2a) e Bragg, (figura 2c) que apresentaram os maiores IER nas três classes de tamanho de sementes, porém, respostas diferentes à variação do tamanho (pois RS 6 Guassupí teve mente do que a Bragg), poderia ser atribuído a dife- 
Tabela 2 - Índice de expansão radial do hipocótilo $(\mathrm{mg} / \mathrm{cm})$ observado em quatro cultivares de soja e três diâmetros médios das sementes. FA/UFRGS, Porto Alegre.

\begin{tabular}{|c|c|c|c|}
\hline \multirow[t]{2}{*}{ Cultivares } & \multicolumn{3}{|c|}{ Diâmetro médio das sementes (mm) } \\
\hline & 5,2 & 6,0 & 6,7 \\
\hline EMBRAPA 19 & $39,6 b^{*}$ & $45,0 \mathrm{a}$ & $41,9 \mathrm{ab}$ \\
\hline Cobb & $47,8 \mathrm{a}$ & $45,4 \mathrm{a}$ & $46,1 \mathrm{a}$ \\
\hline RS 5 Esmeralda & $36,9 \mathrm{a}$ & $38,6 \mathrm{a}$ & $39,8 \mathrm{a}$ \\
\hline CEP 20 Guajuvira & $37,7 \mathrm{a}$ & $40,9 \mathrm{a}$ & $42,0 \mathrm{a}$ \\
\hline
\end{tabular}

*Médias seguidas de mesma letra, na linha, não diferem significativamente pelo teste de Duncan a $5 \%$ de probabilidade.

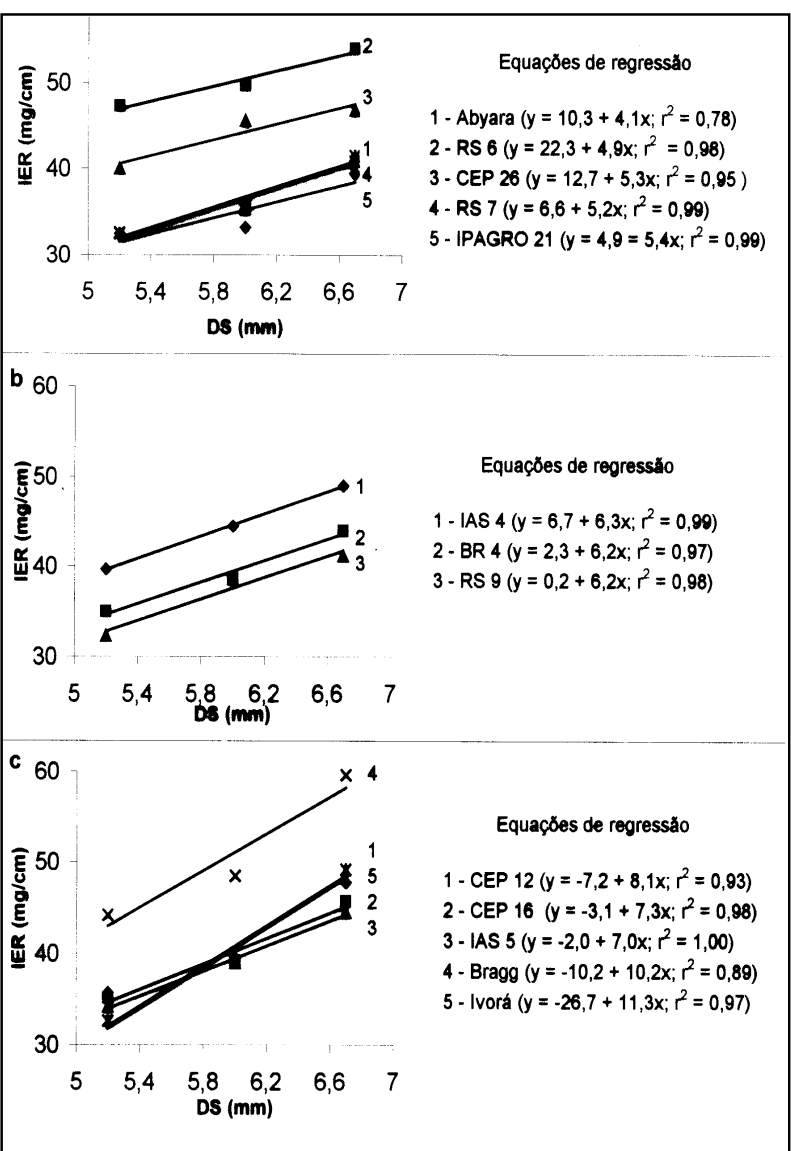

Figura 2 - Índice de expansão radial do hipocótilo (IER) de 13 cultivares de soja, em função do diâmetro médio das sementes (DS). Faculdade de Agronomia da UFRGS, Porto Alegre, RS.

renças genéticas, conforme a hipótese de HOWLE \& CAVINESS (1988).

Os resultados obtidos neste trabalho, sobre o tamanho de sementes, concordam com o obtido por GOESCHL et al. (1966) e KNITTLE \& BURRIS (1979), os quais observaram que sementes maiores originam plântulas com IER do hipocótilo mais alto, o que pode ser uma característica favorável em condições adversas de emergência.

\section{CONCLUSÕES}

1. Os cultivares de soja diferem em comprimento do hipocótilo, o qual variou de 8 a $11 \mathrm{~cm}$;

2. Sementes de soja de maior tamanho originam plântulas com hipocótilo mais curto do que sementes de tamanhos intermediário e pequeno.

3. A maior parte dos cultivares avaliados apresentam acréscimos no índice de expansão radial com o aumento do tamanho de semente, enquanto que outros não mostram esta regularidade de resposta.

\section{REFÊNCIAS BIBLIOGRÁFICAS}

BILBRO, J.B., WANJURA, D.F. Soil crusts and cotton emergence relationships. Transactions of the ASAE, St Joseph, v. 25, n. 6, p. 1484-1487, 1982.

BURRIS, J.S., EDJE, O.T., WAHAB, A.H. Effects of seed size on seedling performance in soybeans: II. Seedling growth and photosynthesis and field performance. Crop Science, Madison, v. 13, n. 2, p. 207-210, 1973.

BURRIS, J.S., FEHR, W.R. Methods for evaluation of soybean hypocotyl length. Crop Science, Madison, v. 11, n. 1, p. 116117,1971

EDWARDS, C.J., HARTWIG, E.E. Effect of seed size upon rate of germination in soybeans. Agronomy Journal, Madison, v. 63, n. 3, p. 429-430, 1971.

GOESCHL, J.D., RAPPAPORT, L., PRATT, H.K. Ethylene as a factor regulating the growth of pea epicotyls subjected to physical stress. Plant Physiology, Lancaster, v. 41, n. 5, p. 877-884, 1966.

HANKS, R.J., THORP, F.C. Seedling emergence of wheat, grain sorghum, and soybeans as influenced by soil crust strength and moisture contend. Soil Science Society of America Proceedings, Madison, v. 21, n. 4, p. 357-359, 1957.

HOWLE, D.S., CAVINESS, C.E. Influence of cultivar and seed characteristics on vertical weight displacement by soybean seedlings. Crop Science, Madison, v. 28, n. 2, p. 321-324, 1988.

JOHNSON, D.R., LUEDDERS, V.D. Effect of planted seed size on emergence and yield of soybeans (Glycine max (L.) Merr.). Agronomy Journal, Madison, v. 66, n. 1, p. 117-118, 1974.

KNITTLE, K.H., BURRIS, J.S. Soybean hypocotyl growth under field conditions. Crop Science, Madison, v. 19, n. 1, p. 37-41, 1979.

REUNIÃO DE PESQUISA DE SOJA DA REGIÃO SUL, 26., 1998, Cruz Alta. Recomendações técnicas para cultura da soja no Rio Grande do Sul e em Santa Catarina 1998/99. Cruz Alta: UNICRUZ, 1998. 133 p. 